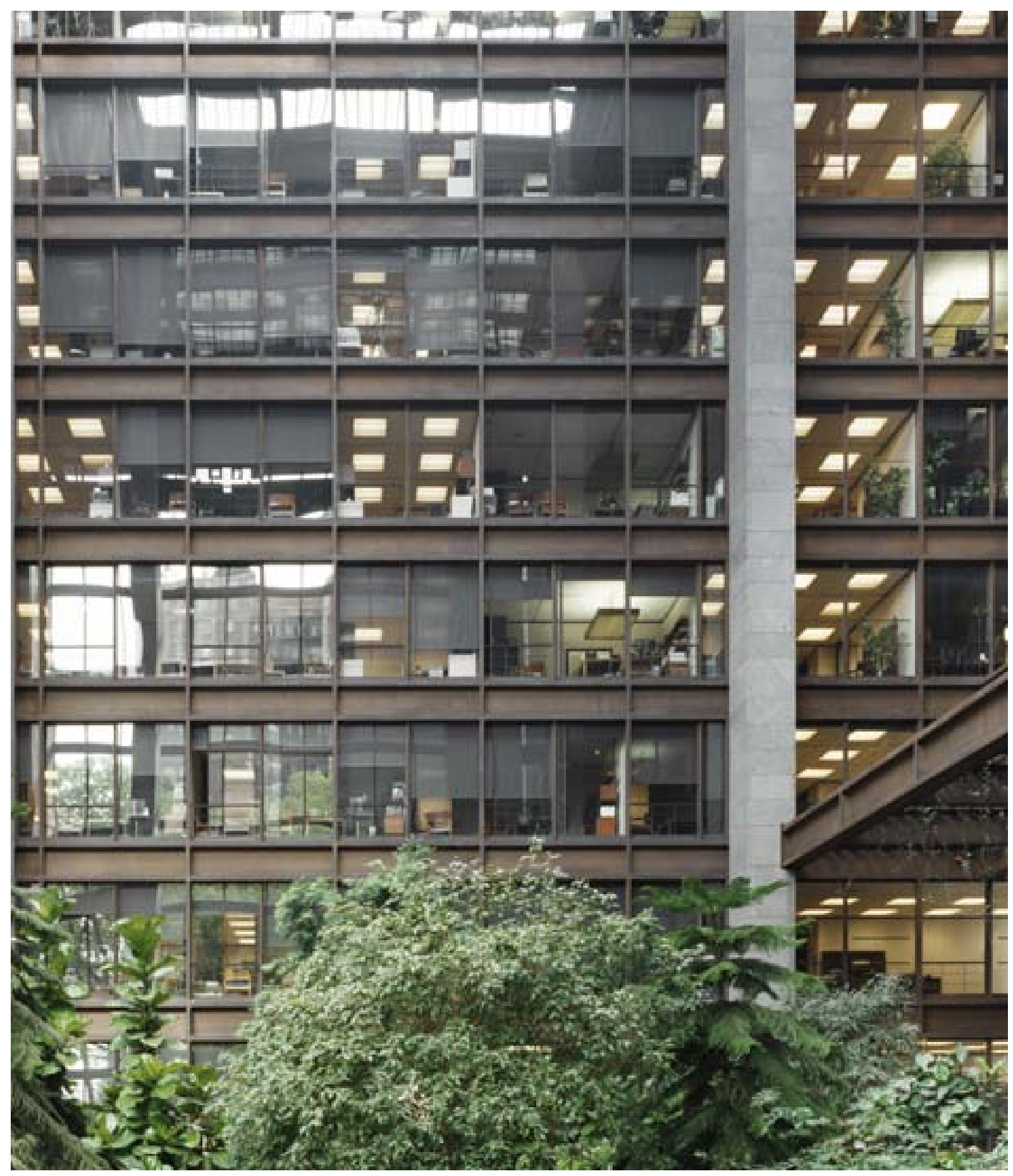




\section{The Learning Machine and the Spaceship in the Garden. Al and the design of planetary 'nature' Andrew Toland}

Planetary-scale artificial intelligence systems are increasingly being promoted by technology companies in the forms of projects such as Microsoft's "Al for Earth" and Google's "Earth Engine". This article interrogates some of the conceptual dimensions and history of the "dashboard" approach to the management of "spaceship earth" within art, architecture and landscape architecture, and considers the implications of the increasingly entangled "design" work that brings together nature as data, machine learning, robotics and autonomous technologies.

\section{KEYWORDS}

Architecture and Technology, Architecture and Robotics, Architecture and Artificial Intelligence, Landscape Architecture and Remote Sensing, Landscape Architecture and the Global Environment

\section{PALABRAS CLAVE}

Arquitectura y tecnología, arquitectura y robótica, arquitectura e inteligencia artificial, paisajismo y teledetección, paisajismo y medioambiente global

"You may very appropriately want to ask me how we are going to resolve the ever-acceleratingly dangerous impasse of world-opposed politicians and ideological dogmas. I answer, it will be resolved by the computer. ... So, planners, architects, and engineers take the initiative. Go to work..... R. Buckminser Fuller, Operating Manual for Spaceship Earth, $1963^{1}$

"The outcome has been pretty much the same...

The final image of the garden is always of it overgrown or dead".

Joseph Santarromana, co-director of the Tele-Garden Project, $1996^{2}$

In December 2017 the journal Nature published an article by Microsoft's first chief environment scientist, Lucas N. Joppa ${ }^{3}$. In it, he called for the creation of "an artificial-intelligence platform for the planet"4. This call to arms was an expansion of a series of discussions that have

\section{Andrew Toland}

Lecturer in Landscape Architecture at the University of Technology Sydney. He holds degrees in architecture, law and economics. His research examines the cultural and social dimensions of large-scale landscape infrastructures and technologies, the conceptualisation of the nonhuman in design and landscape practices, and discourses of realism, reality and the real in architecture, landscape architecture and urbanism. His writing has been published in Scapegoat, Cabinet, Scroope: the Cambridge Journal of Architecture and Architecture Australia, and a recent book chapter in A.M. Rademacher \& K. Sivaramakrishnan (eds), Places of Nature in Ecologies of Urbanism, Hong Kong University Press, 2017. Orcid ID 0000-0003-2052-5720

Fig. 01

Ford Foundation Garden, New York, by landscape architect Dan Kiley, 1964. Photograph by David Leventi, 2013. (detail). 
been occurring around the issue of big data, artificial intelligence and the environment, and was tied to the launch of a 5-year Microsoft research partnership program titled "Al for Earth". At first glance, this notion summons up the image of a kind of whole earth "dashboard" or "control panel" for the age of Al (fig. 02) -a Silicon Valley update of Buckminster Fuller'sOperating Manual for Spaceship Earth or Stewart Brand's Whole Earth Catalog for the big data era (one might ask if this is yet another echo of the cooption of the visionary or the countercultural by Silicon Valley). This article considers a number of recent technological developments that are rapidly converting 'nature' into data and data into design: data that can be collected, processed, analysed and, in the most ambitious imaginings, physically manipulated via these feedback systems back out in the "real" or "natural" world. I am interested to consider the implications of these technologies for the way in which architects and landscape architects conceive of "design with nature" within a large continuum of culturenature interactions, and the ways in which algorithmic design in architecture might be migrating out of the formal and structural domains, where it has been operating for some time now, and out into the domain of "nature".

The Al for Earth project emerges out of a line of earth sciences research that has been gaining momentum rapidly over the past few years. According to a report titled "A Dashboard for the Earth" posted on The Dirt, the online publication of the American Society for Landscape Architects, by its editor Jared Green, a 2016 conference hosted by the Renewable Natural Resources Foundation (RNRF) on "Harnessing Big Data for the Environment" envisaged new technologies continuously feeding "up-to-the-minute data on ecosystems functions" like a "“"Bloomberg terminal" for the planet". Nonetheless, as Fuller's book illustrates, the fantasy of a whole earth dashboard, control room or cockpit has been present in architectural thinking for quite some time. Despite the clickbait of the title, Green regrets to inform us that the experts at the RNRF congress confirm that we are "nowhere near" this fantasy of a benign, Al-assisted, total control over the piloting of "spaceship earth". The stumbling block, reports Green, lies in the difficulty of satisfactorily integrating

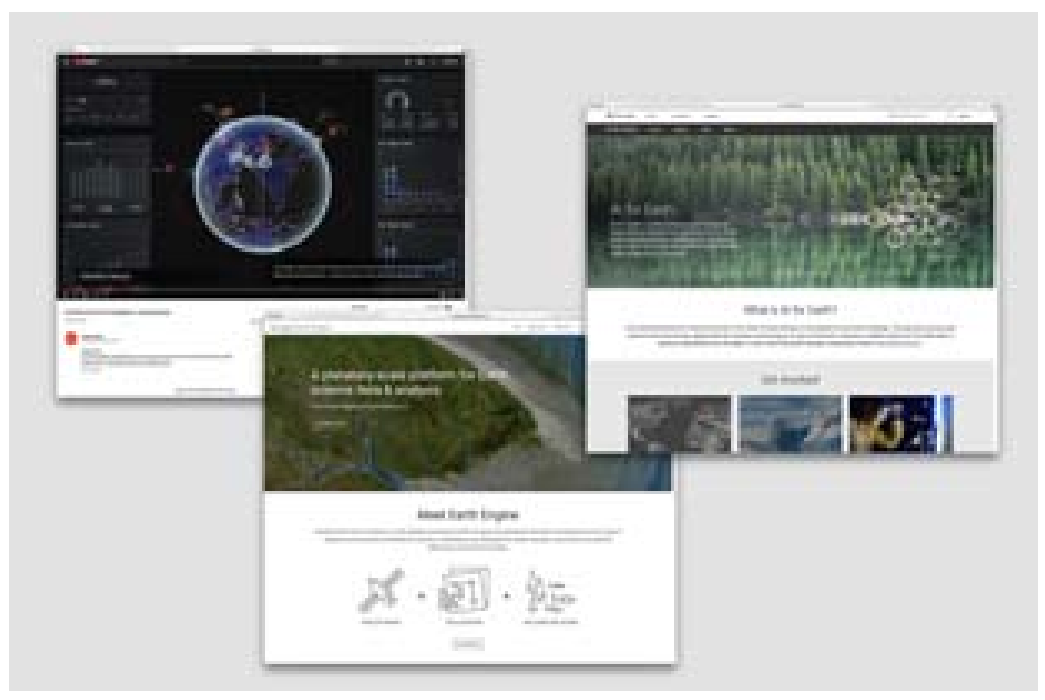

02 
environmental with social and economic data ${ }^{7}$. In the actual summary of the congress published in the RNRF's Renewable Resources Journal, the road block is presented as arising more from the lack of "availability" of "social data" (by which the authors really seem to mean its epistemological untrustworthiness, its tendency to become contaminated by normative biases). In this rendition, the promise and efficacy of big data is sacrificed on the altar of "big judgment":

\footnotetext{
"Typical decisions about the use and conservation of natural resources, including land-use and environmental-standards decisions, must consider social, economic and political factors. As has been the case since people first began debating the value of a duck or open space or how much pollution is permissible, social factors are considered in addition to physical assessment data. However, it is the case that social data are not [as] available as big data, and concerted efforts to apply big data processes to environmental decision-making are nearly non-existent. Thus, most environmental decisions will continue to be made through human integration of social and physical data-big judgment" ${ }^{\text {. }}$.
}

Concern about the empirical falling victim to the normative is also a concern of Microsoft chief environment officer Joppa's recent Nature article (Joppa also participated in the December 2016 RNRF congress), but he is more sanguine about the possibility of a resolution -the empirical can trump normative biases if only data were even "bigger". He argues that "decisions about what actions to take [in response to environmental issues] will be easier to make -and less vulnerable to politicisation- if we know [even more about] what is happening on Earth, when and where". . What is notable here is the latent discomfort of the scientists with social and political judgments.

Yet it is also interesting to note the translation that occurs between the position of the scientists and that of the architect (or, more specifically in this instance, the landscape architectural writer) in the way the discussion of the 2016 RNRF congress is rendered in Green's article. The RNRF is a U.S. public policy research foundation made up of various earth sciences and related professional bodies (for example, the American Geophysical Union, the American Meteorological Society, the Society of Environmental Toxicology and Chemistry), and includes the American Society of Landscape Architects Fund, which may be one of the reasons for Green's reporting on the congress in The Dirt in the first place. Green's report achieved some measure of wider popular dissemination, being picked up and republished in identical form by The Huffington Post a few months later (and updated at the start of this year) ${ }^{10}$. Green's representation of these emerging technologies seems to be conditioned by the recent interest in urban and media studies circles with real-world projects for urban "control rooms", "operations centers" and "dashboards"", along with the allure of "deep learning neural net" $\mathrm{Al} /$ machine learning technologies (the articles on both The Dirt and The Huffington Post use the same image credited to the ExtremeTech website visualizing a neural network in the manner of a human biology documentary about brain synapses and neurotransmitters) ${ }^{12}$. Rather than scientists' discomfort with the messiness of politics, Green's repackaging seems deliberately tap into-cultural anxieties about artificial intelligence, surveillance and control. 
However, the reality of Microsoft's planetary Al platform outlined by Joppa in his Nature article is really a partnering system for connecting technology experts with environmental organisations to apply algorithmic data analysis to "monitor, model and ultimately manage Earth's natural systems"13. The actual discussion focuses around cases of the automation of data collection and analysis, but still presents a model in which the "management" component required to implement the results of the analysis operates via the traditional process of decision-making by land use planners. Nonetheless, the prospect of an Al whole earth dashboard is an intriguing one -especially in relation to other recent applications of remote sensing, data centralisation and artificial intelligence.

In her analysis of "Urban Dashboards", Shannon Mattern traces schemes for city governance "operations centres" and "Dashboard Governance" and unpacks their ideological underpinning ${ }^{14}$. The objective of these urban control rooms is to provide real-time "performance" information to city governments or related state institutions: surveillance video, crime statistics, transportation and traffic systems monitoring, live information on utilities and infrastructure, weather data, accident and emergency systems, as exemplified in such projects as the Operations Center for the City of Rio, designed by IBM. Mattern makes a connection to the etymological origins of the term "dashboard" -a mid$19^{\text {th }}$ century coinage for timber or leather skirting attached to a carriage that served as a mudguard against dirt kicked up by the horses hoovesobserving that their electronic derivatives similarly serve to sanitise or bracket out the real "mud" of urban dynamics and processes, converting them into conventionalised variables and translating them into representable "data" that "structure the agency and subjectivity of the dashboard's users", determining how officials intervene in the system and prescribing the "tools" that they use ${ }^{15}$. Although not discussed by Mattern, it is conceivable that operational decisions could be facilitated or augmented by $\mathrm{Al}$, and this is already being seen in the new systems of $\mathrm{Al}$-supported urban and social governance being set up by the Chinese state that harness networks of millions of security cameras and even augmented glasses, and algorithmically link them to facial recognition software and other databases to facilitate arrests, calibrate individuals "citizen scores" and incentivize "good behaviour"16.

$\begin{array}{ll}\text { ARCHITECTURE } & \text { Whilst some software engineers are clearly } \\ \text { AS AN } & \text { working to design systems of near-instantaneous } \\ \text { INSTRUMENT OF } & \text { social control, architecture itself has a history of } \\ \text { ENVIRON MENTAL } & \text { designing much slower systems that have used } \\ \text { CONTROL } & \text { environmental control to project certain ideals of } \\ & \text { social (and global) order. In her study, Outlaw }\end{array}$

Territories, Felicity D. Scott has traced earlier instances of architecture's implication in global "environmental control" in the sense of its complicity in shaping environmental, political and geopolitical conditions in the service of global, corporatised managerialism in the private and public sectors, emanating from the United States ${ }^{17}$. Her analysis of Kevin Roche's design for the Ford Foundation headquarters in New York examines the giant interior garden designed by Roche with the landscape architect Dan Kiley (fig. 03). The garden is an enclosed microcosm, with plants species from around the world, climate-controlled, and fed by artificial fertiliser injectors and an automatic irrigation system. Contemporary observers could not 
help but get the signals that this high-tech garden was a symbolic space of environmental and global control. Scott quotes from a 1968 commentary in Life magazine, which interpreted it as a vision of future cities in which, to make urban life liable in the face of overwhelming pollution, "[e]ntire blocks will be glassed over, planted with greenery and controlled by thermostat"1. A quotation from a Village Voice interview with a Ford Foundation manager, bears out Scott's point that this "controlled, internalised environment translated into a sense of control at a global scale"; the manager gushes, "You are able to see urban and rural settings and two different seasons of the year at the same time.... It helps me keep thinking in global terms"19. In the context of the time, and the Pax Americana that the Ford Foundation and its headquarters embodied, global control and US hegemony was to be channelled through a system of international institutions and aid. It was a managerial system of control, whose levers were operated by figures in the mould of William H. Whyte's "Organization Man", figures who, in the real world, took the form of people like Ford Motor Company's "Whiz Kid" President, and the Kennedy and Johnson administrations' data-driven (and Vietnam War body count-escalating) Secretary of Defense, Robert McNamara. The Ford Foundation's New York headquarters might on its face seem a far cry from the jungles of Vietnam, but Scott convincingly demonstrates its ideological entanglement in the system that produced Taylorist managers and warmongering accountants alike.
Fig. $\mathrm{O3}$

Ford Foundation Garden, New York, by landscape architect Dan Kiley, 1964.

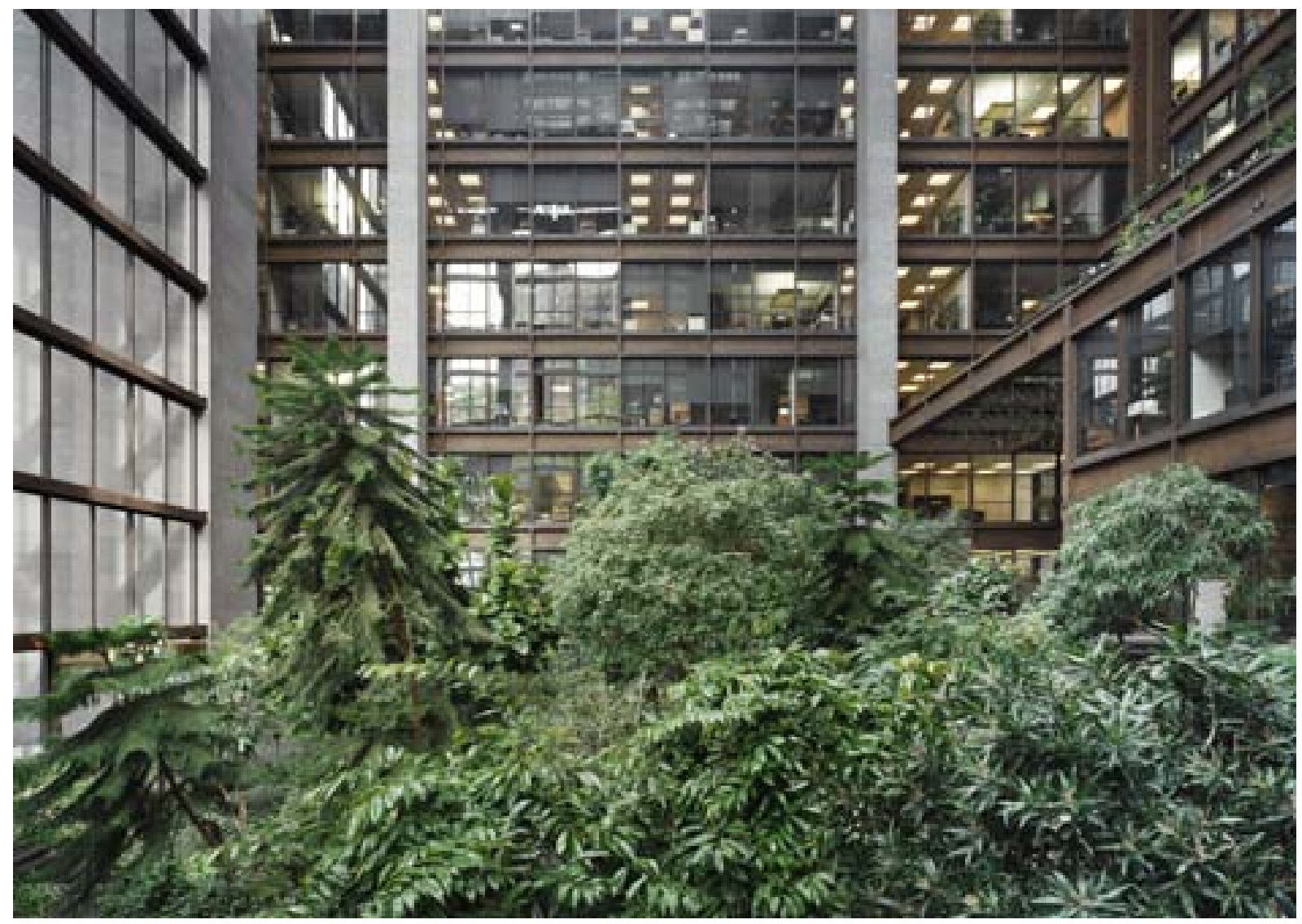


THE (DIS)

ORDERED

GARDEN AS AN

INSTRUMENT OF

SOCIAL CONTROL
Whilst Roche and Kiley's atrium garden was a vegetational scale model of the American empire, thirty years later, a different global model of microcosmic natural control for the networked age emerged in the form of the TeleGarden Project, an art and computation project by Ken Goldberg and Joseph Santarromana designed to test an emergent online community's capacity to monitor and affect conditions in the "real world". From a contemporary vantage point, the Tele-Garden, fittingly, lives on in an (almost entirely) electronic afterlife. It continues to exists on the internet as archived webpages, videos on YouTube, in published surveys of digital and electronic art, and as the inspiration for a 2000 scholarly book edited by one of its creators ${ }^{20}$. In a high-resolution jpeg, downloadable from his website, it sits spotlighted in front of a black backdrop, neatly arranged on a black carpet with its umbilical connections of water, power and data connections disappearing off beyond the picture frame (fig. 04). In its neatly arrayed planting bed, we see a tidy assembly of cultivars, the colour-bursts of their flowers, the varied greens of their leaves. On the robotic arm is the only text in the image, 'adept', the almost too perfect brand-name of the robot's manufacturer.

The Internet Archive's Wayback Machine contains 620 saves for the homepage of the Tele-Garden installation at the Ars Electronica Center in Linz, Austria ${ }^{21}$. The installation first went live on the World Wide Web in June 1995 from a laboratory at the University of Southern California. In September 1996 it was moved into the lobby of the Ars Electronica Center until it was decommissioned in August 2004. It consisted of an 18-inch-deep planting tray, an industrial robot arm with a custom attachment containing a camera, lighting, and a series of pneumatic actuators that delivered water and allowed the digging of small holes and planting of seeds. Crucial to the success of the Tele-Garden was its web-connected camera which allowed live images to be transmitted to its remote community of member-"gardeners". It was this crucial feedback loop that allowed the "gardening" to take place, while at the same time generating a spontaneous online social network around the project. Additionally, the system was programmed to enable members to request a series of time-lapse images over several weeks; the robotic arm would return the camera to the specified position during non-peak periods to periodically record the images ${ }^{22}$.

In retrospect, it is now clearly possible to see the Tele-Garden within a lineage of robotic cultivation whose most recent incarnations range from open-source 'FarmBots' for domestic automated for produc$\operatorname{tion}^{23}$, through to the application of remote sensing, autonomous vehicle and Al technology in industrial agriculture ${ }^{24}$. The initial framing of the TeleGarden Project, however, somewhat grandiosely placed it within a social and technological evolutionary trajectory, captured in two epigraphs on the "About" page on the project's website -a quote from H.W. Janson's History of Art:

"The Neolithic Revolution ... began sometime around 8000 B.C. when humans made their first successful attempts to domesticate animals and food grains ... Having learned how to assure their food supply by their own efforts, they settled down in permanent village communities..." ${ }^{25}$. 


\section{And one from Compton's Encyclopedia:}

\begin{abstract}
"Gardens are as old as civilization itself... vivid descriptions by scientists, naturalists, and historians have far out-lasted those gardens that first inspired them. Aristotle...made detailed observations during his two-year study of the wild gardens on the island of Lesbos. His firm belief that the natural world should receive greater scientific attention paved the way to much of what was to follow..." ${ }^{26}$.
\end{abstract}

This latter quote reinforces the symbolic and epistemological significance Tele-Garden's rudimentary CCD web camera, and places it within the model of the unidirectional flow of knowledge and information in science, from the natural world into the eye and mind of the enlightened observer. From an architectural and urbanist perspective, however, it is the first quotation, that is immediately telling. Janson's verbal sketch of the evolution of human societies, systems of production and human settlement is instantly recognisable as the conventional post-Enlightenment narrative about the pathway from nomadism through rural agriculture to commercial and industrial cities. This is the stereotyped model of urban development from hunter-gatherer to developed commercial city conveyed graphically in Patrick Geddes' famous 1909 "Valley Section of Civilization". Just as this historical trope posits a social Darwinian trajectory of technological and intellectual progress from the "primitive" to the "civilized", the Tele-Garden similarly operated as an experimental proof that self-organised and enlightened cooperation was the next evolutionary stage of online communities. If the users didn't selforganise into communities of collective interest then the garden either died or became too overgrown (why it needed to take the form of a neatly planted, weeded and orderly suburban flower bed is never really clear from its progenitors' commentaries).

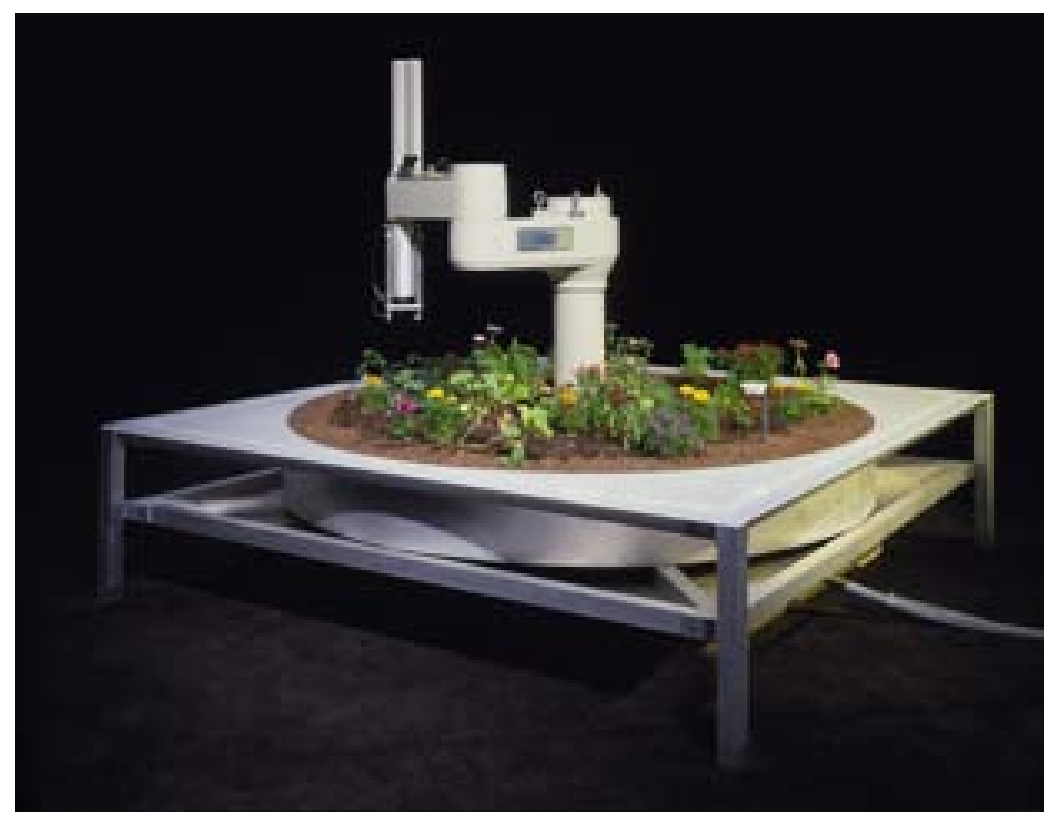

04
Fig. 04

The Tele-Garden by Ken Goldberg and Joseph Santarromana, University of Southern California and Ars Electronica Museum, Linz, Austria, 1995-2004. 
FROM SCALE MODEL TO ONE-TO-ONE
The interior garden at the Ford Foundation and the Tele-Garden are mirror images of one another. The Ford Foundation garden stands at the end of a long lineage of microcosmic gardens, like the physic garden and the later botanical garden, that draw together different botanical materials in the act of modelling a global situation to be appreciated from a single, embodied human perspective. The Tele-Garden, on the other hand, brings together multiple human perspectives, dispersed across the entire global reach of the early internet, for a disembodied engagement focused on a single botanical terrain (it appeared that the particular species planted in the Tele-Garden were not treated as an especially significant part of the project). Nonetheless, both the Ford Foundation garden and the Tele-Garden are part of the fusing of the mechanical and electronic with the natural and human, and thus part of an ongoing continuum entwining episteme, techne and phusikos in the progression of modernity.

Seen in light of this progression, the more recent global Al projects enlarge these ambitions to a planetary scale; these are no longer scale models or microcosms, instead they recall the image of Borges of the knowledge embedded in representations and the thing itself in a one-to-one relationship -"a Map of the Empire whose size was that of the Empire"27.

AI TO THE

RESCUE?

Returning to Green's representation of the RNRF congress as a vision of a whole earth dashboard, and positioning it at the end of a twenty-year aro from the Tele-Garden and its primitive (human) feedback system of remote-"sensing" and response, we can begin to imagine an enlargement from the real-time data and feedback loops of urban dashboards considered by Mattern towards a vast integrated and machine-directed system of environmental-sensing and response. In considering the discussions at the RNRF congress, we might also return to Buckminster Fuller and earlier attempts within the international discourses of development and environmental conservation to establish new comprehensive systems of acquiring information. In the "Declaration of the Vancouver Symposium" (whose signatories included Fuller himself), progressive environmental planning at a national scale was said to demand:

\footnotetext{
"New academic institutions and types of research as well as new and appropriate methods of collecting and organizing data ... to underpin the new effort in settlements policy. In this context, national inventories of types of land, natural ecosystems, mineral reserves, pressures and movements of population and other basic forms of information are often out of date or nonexistent" ${ }^{\text {"28. }}$.
}

Fuller had already modelled such a system of comprehensive information collection in his World Resource Inventory, and instrumentalised it in what is still perhaps the most-nearly realised world environmental dashboard: his so-called "World Game". Whilst at the Southern Illinois University in Carbondale, he sought to have the massive computerised simulation infrastructure intended to underpin the World Game constructed on the campus, with a giant screen to display real-time data 
on global resources. The complexity of implementing Fuller's grandiose global inventory, or even the more modest collective national-level approach of the Vancouver Declaration, remains elusive even in the age of Big Data, and its agency for Fuller's eco-utopian vision, even more so.

Fuller attempted to advance a model for a global environmental rebalancing by refuting Maltusian (and, closer in time to him, the Club of Rome's and Jay Forrester's) scarcity models of world resources. His World Game and its comprehensive real-time data collection was designed to make this global resources cornucopia visible to all. Fuller's Pollyanna-ish attitude seems pitiably naïve when viewed from an age which measures human environmental impacts along the exponential curve of resource depletion and species loss of the Great Acceleration. Here, the fears of scarcity, and the ever-present spectre of total systems collapse, return with a vengeance. demanding the 'big judgment' of essentially political decisions about where and what to endow with environmental value. The "Al for Earth" and "Big Data for the Environment Initiatives" hold out the promise of a kind of global environmental dashboard, presenting us with all that 'up-tothe minute' big data to allow us (or our governments) to make the ultimate politico-environmental "Big Judgments".

This cognative-ideological model of global environmental 'design' again harkens back to the 'spaceship earth' notions of the 1970s. Peder Anker has argued that these modes of discourse about the environment in the 1970s used imagery of self-contained, closed-system life-inspace as a way of translating into architectural design a much wished-for model of a peaceful, rational and environmentally sound alternative to the real-world conflicts, irrationality and environmental crises of the time ${ }^{29}$. For instance, the landscape architect lan McHarg used the image of earth as a space capsule repeatedly in his influential Design with Nature ${ }^{30}$. In his keynote address to the 1970 American Institute of Architects' "Day of Awareness" conference, he claimed that the "real definition of architecture" was the "business of adaptation for survival", and that adaptation required "design" to be thought of as adjustment of the built environment to support human planetary survival just as the systems and processes of the space capsule had to be designed to support the astronaut's survival"'31. Within this model, the systems failure comes not from the technology, but from the faulty interventions of its human operators. In the Tele-Garden, the first growing season was terminated by the over-watering of a single user who flooded the garden; in other instances, the garden would become overgrown without members banding together to cooperatively manage pruning, weeding and replanting across a larger area. In the contemporary incarnation of the Tele-Garden, the FarmBot automates many of these processes with "Sequences", "Regimens", and "Farmware", including the use of image-recognition processes to detect weeds, which simplifies the production of coded cultivation sequences and management. Increasingly, the planetary scale of remote sensing and modelling projects and these small scale remote and robotic cultivation management processes are converging. At a planetary scale, Joppa, the Microsoft chief environment officer, presents a case that those judgments are also better removed from humans: "We need artificial intelligence to save us from ourselves", he says, "My worry is Al won't come soon enough ${ }^{32}$. More specifically, Al's work will be, in Joppa's view, finding trends and predicting scenarios drawing on big data: "We are starting to put together the building blocks of a system that is able to monitor Earth's operating system, and figure out how to 
debug it when things start to go wrong" ${ }^{33}$. There is a risk here, however, that this thinking runs the risk of falling victim to the fallacy of composition, a concept popularised by Keynes as part of his critique of classical economics. Similarly, this is an issue that will be instantly familiar to architects as a question of scale and of the relationship of parts to whole. The fallacy draws attention to the problem that just because something is true of a part of the system, or even of all parts of the system treated individually, it may be risky to infer that it is also true at a whole-system level.

What is most telling about the Tele-Garden precedent is the way in which it was governed by human passions. One of the fantasies of $\mathrm{Al}$ (in the scientific and tech-investor world, as opposed to the pop cultural world of Al dystopias) is that it is able to remove human irrationality and replace it with algorithmically perfect chains of logic -the ultimate fulfilment of the Enlightenment project (and perhaps the true birth of homo economicus). Ultimately, however, this may prove to be yet another instance of magical thinking (in its strictest anthropological sense). The recent debates around the inherent racism of algorithms illustrate the extent to which they literally encode cultural prejudices ${ }^{34}$. One can readily imagine the same being true for projects around Big Data, Al, robotics, the environment, and whole earth "dashboards". Without even going to the planetary scale, the propositions for remote-sensing, big data and Al already illustrate some of these blindspots. According to the World Economic Forum, "Al-augmented agriculture", with its "automated data collection, decision-making and corrective actions via robotics [will] allow early detection of crop diseases and issues, ... provide timed nutrition to livestock, and generally ... optimise agricultural inputs and returns based on supply on demand". The language is both telling and puzzling, especially coming from the WEF, given that it was (and in many instances still is) asserted that it is only through the "invisible hand" of the market that these forces can appropriately be optimised. Admittedly, the argument would no doubt be that the market it is driving the technology investment that will produce this Al-perfected agricultural utopia, and so it is indeed the market that should ultimately be credited. At the same time, though, it also looks like an admission of (traditional) market inefficiency or even failure. Joppa cites GIS data analytics firm Descartes Labs and also agricultural equipment manufacturer John Deere's acquisition of Blue River Technology as the agricultural instances of his "inspirational examples" but one imagines that the venture capital and hedge fund-investor assessments of these projects imagine (will shape their development) towards profit-maximisation, allowing every more instantaneous and finely calibrated automated commodity futures trading in the case of the former, and more aggressive large-scale corporatized farming tailored to the product and new-market creation drives of the food industrial complexfood industrial complex, in the case of the latter.

Tech-investors and software engineers have all become Buckminster Fullers now -the computer is the deus ex machina that will save us. Cultural practitioners, however, architects and landscape architects among them, need to find avenues into this space(ship), to wrestle the controls of the dashboard away from the messiahs of technology and capital, to find alternative and critical ways to "go to work" (pace Bucky) with these technologies. As "nature" more and more transforms into "data", the challenge is for designers to construct environmental futures, as opposed to "environmentally-controlled" ones. RA 
01. FULLER, R. Buckminster, Operating Manual for Spaceship Earth, E.P. Dutton, New York, 1978, pp. 132-133.

02. Joseph Santarromana, co-director of the Tele-Garden Project, quoted in STEDMAN, Nancy, and DITLEA, Steve, "Thriving Community is Seeded by Tele-Gardening on the Web", The New York Times, August 2, 1996, <http:// politics.nytimes.com/library/cyber/ week/0802garden.html >, accessed February 22, 2018.

03. JOPPA, Lucas N., "The case for technology investments in the environment", Nature, 2017, 552, pp. 325-328.

04. Ibid.

05. See <https://www.microsoft.com/en-us/ aiforearth>, accessed February 26, 2018.

06. GREEN, Jared, "A Dashboard for the Earth", The Dirt, August 12, 2016, <https:// dirt.asla.org/2016/12/08/a-dashboard-forthe-earth/>, accessed February 23, 2018.

07. Ibid.

08. "Executive Summary: Observations for the Future", Renewable Resources Journal, 2016, 30(4), p. 4.

09. JOPPA, Lucas N., op. cit.

10. GREEN, Jared, "A Dashboard for the Earth", The Huffington Post, January 19, 2017, updated January 20, 2018, <https:// www.huffingtonpost.com/jared-green/adashboard-for-the-earth_b_14256028. html>, accessed February 23, 2018.

11. For example, see MATTERN, Shannon, "Mission Control: A History of the Urban Dashboard", Places Journal, March 2015, <https://doi.org/10.22269/150309>, accessed 25 Feb 2018

12. TEMPLETON, Graham, "Facebook is working on "deep learning" neural networks to learn even more about your personal life", ExtremeTech, September 23, 2013, <https:// www.extremetech.com/computing/167179facebook-is-working-on-deep-learningneural-networks-to-learn-even-more-aboutyour-personal-life>, February 26, 2018.

13. JOPPA, Lucas N., op. cit.
14. MATTERN, Shannon, op. cit.

15. Ibid.

16. MITCHELL, Anna, and DIAMOND, Larry, "China's Surveillance State Should Scare Everyone", The Atlantic, February 2, 2018, <https://www.theatlantic.com/ international/archive/2018/02/chinasurveillance/552203/>, accessed February 5, 2018.

17. SCOTT, Felicity D., Outlaw Territories: Environments of Insecurity/Architectures of Counterinsurgency, Zone Books, New York, 2016

18. Quoted in Ibid., p. 50. In another echo of Fuller, this description summons to mind Fuller's 1960 "Dome Over Manhattan" project.

19. Quoted in Ibid., p. 52.

20. GOLDBERG, Kenneth (ed.), The Robot in the Garden: Telerobotics and Telepistemology in the Age of the Internet, MIT Press, Cambridge, MA, 2000.

21. Before that, the homepage was hosted at <http://www.usc.edu:80/dept/garden/>. That page continued to document the project until some time in early 2017 . The final Wayback Machine extant save for that webpage is for April 25, 2017. At the date of the next save (June 13, 2017), the web address returned a "Page Not Found" message.

22. "Technical Brief", SPIE Newsletter, Spring 1996, available via <http://web. archive.org/web/19970411230153/ telegarden.aec.at/cgi-bin/knapsack/html/ info.html>, accessed Feb 22, 2018.

23. See <https://farm.bot/>, accessed February 21, 2018.

24. For example, see < http://robohub.org/ farming-with-robots/>, February 21, 2018.

25. <http://web.archive.org/ web/19980203215401/http://telegarden. aec.at:80/cgi-bin/gard-custom/html/intro. html>, accessed Feb 22, 2018.

26. <http://web.archive.org/ web/19980203215401/http://telegarden. aec.at:80/cgi-bin/gard-custom/html/intro. html>, accessed Feb 22, 2018.
27. BORGES, Jorge Luis, "On Exactitude in Science", in Jorge Luis Borges: Collected Fictions, translated by Andrew Hurley, Penguin, New York, 1998, p. 325.

28. "Declaration of the Vancouver Symposium", Ekistics, 42: 252, 1976, pp. 267-272.

29. ANKER, Peder, "The Closed World of Ecological Architecture", Journal of Architecture, 10:5, 2005, pp. 527-552.

30. McHARG, Ian, Design With Nature, Doubleday, Garden City, NY, 1969.

31. McHARG, lan, "Architecture in an Ecological View of the World", AIA Journal, 54, November 1970, pp. 47-51.

\section{Quoted in GREEN, op. cit.}

33. "Executive Summary: Observations for the Future", op. cit., p. 7.

34. Eg, see BURANYI, Stephen, "Rise of the racist robots - how $\mathrm{Al}$ is learning all our worst impulses", The Guardian, August 8, 2017, <https://www.theguardian.com/ inequality/2017/aug/08/rise-of-the-racistrobots-how-ai-is-learning-all-our-worstimpulses>, accessed February 18, 2018.

35. JOPPA, Lucas N., op. cit
RA. Revista de Arquitectura Núm. 20 - 2018

P. 216-227 